\title{
Prevalence and factors associated with the use of antibiotics in non-bloody diarrhoea in children under 5 years of age in sub-Saharan Africa
}

\author{
Asa Auta, ${ }^{1}$ Brian 0 Ogbonna, ${ }^{2}$ Emmanuel 0 Adewuyi, ${ }^{3}$ Davies Adeloye, ${ }^{4,5}$ \\ Barry Strickland-Hodge ${ }^{6}$
}

${ }^{1}$ School of Pharmacy and Biomedical Sciences, University of Central Lancashire, Preston, UK

${ }^{2}$ Department of Clinical Pharmacy and Pharmacy Management, Faculty of Pharmaceutical Sciences Nnamdi Azikiwe University, Awka, Nigeria

${ }^{3}$ Statistical and Genomic Epidemiology Laboratory, Institute of Health and Biomedical Innovation, Queensland University of Technology, Brisbane, Australia ${ }^{4}$ Nigerian Urban Reproductive Health Initiative, Abuja, Nigeria ${ }^{5}$ Johns Hopkins Centre for Communication Programs, Baltimore, Maryland, USA

${ }^{6}$ Faculty of Medicine and Health, School of Healthcare, University of Leeds, Leeds, UK

Correspondence to Dr Asa Auta, School of Pharmacy and Biomedical Sciences, University of Central Lancashire, Preston PR1 2HE, UK; aauta@uclan.ac.uk

Received 4 October 2017 Revised 2 March 2018 Accepted 7 March 2018 Published Online First 19 March 2018

Check for updates

To cite: Auta A, Ogbonna BO, Adewuyi EO, et al. Arch Dis Child 2019:104:518-521.

\begin{abstract}
Objectives To estimate the prevalence and determine the factors associated with the use of antibiotics in the management of non-bloody diarrhoea in children under 5 years of age in sub-Saharan Africa (SSA).

Methods We conducted a meta-analysis of demographic and health survey data sets from 30 countries in SSA. Pooled prevalence estimates were calculated using random effects model. $\mathrm{X}^{2}$ tests were employed to determine the factors associated with the antibiotic use.
\end{abstract}

Results The pooled prevalence of antibiotic use among cases of non-bloody diarrhoea in children under 5 years of age was $23.1 \%$ (95\% Cl 19.5 to 26.7). The use of antibiotics in children with non-bloody diarrhoea in SSA was associated with $(p<0.05)$ the source of care, place of residence, wealth index, maternal education and breastfeeding status.

Conclusion We found an unacceptably high use of antibiotics to treat episodes of non-bloody diarrhoea in children under the age of 5 in SSA.

\section{INTRODUCTION}

Diarrhoea is one of the leading causes of morbidity and mortality in children under 5 years of age worldwide with about 1.7 billion episodes and 578000 deaths every year. ${ }^{1}$ Most of these episodes and deaths occur among children in Africa with about 440 million cases and 350000 deaths annually. ${ }^{2}$

The appropriate treatment of diarrhoea is simple, yet it remains a problem in many low-income and middle-income countries (LMICs). Recent reviews of diarrhoea management in children in LMICs have revealed a high degree of inappropriate practice including excessive fluid curtailment and antibiotic prescribing. ${ }^{3-5}$ The existing WHO guideline recommends the use of oral rehydration solution (or an intravenous electrolyte solution in cases of severe dehydration) as well as zinc supplementation and continued feeding for the treatment and management of diarrhoea in children. ${ }^{6}$ The guideline only recommends the use of antibiotics in cases of bloody diarrhoea, suspected cholera or associated sepsis.

The inappropriate use of antibiotics in children with diarrhoea can result in the development of antibiotic resistance. In addition, the majority of antibiotics can increase the risk of diarrhoea because of their effect on gut microflora. ${ }^{7}$ Very few studies have focused on understanding the extent of antibiotic use in episodes of non-bloody diarrhoea in children in sub-Saharan
What is already known on this topic?

- The appropriate treatment of diarrhoea is simple, yet it remains a problem in many lowincome and middle income countries.

- Most cases of non-bloody diarrhoea in children are self-limiting and are caused by microorganisms which are not susceptible to antibiotic therapy.

- Use of antibiotics to treat non-bloody diarrhoea in children increases the risk of adverse effects and the development of resistant bacteria.

\section{What this study adds?}

- We utilised nationally representative data to estimate the prevalence of antibiotic use in episodes of non-bloody diarrhoea in children under the age of 5 in sub-Saharan Africa (SSA).

- We found that over one in five cases of nonbloody diarrhoea were treated with antibiotics in SSA.

- We highlight the need to educate prescribers and parents in SSA on appropriate management of diarrhoea and the consequences of inappropriate use of antibiotics in children.

Africa (SSA). Rogawski et al $^{8}$ reported that $48.2 \%$ and $21.5 \%$ of cases of non-bloody diarrhoea in Haydom in Tanzania and Venda in South Africa, respectively, were treated with antibiotics. Also, Opondo et al found that $64.5 \%$ of cases of non-bloody diarrhoea in children were treated inappropriately with antibiotics in eight district hospitals in Kenya. However, these studies were not nationally representative and did not explore the factors associated with the use of antibiotics in children with non-bloody diarrhoea. We conducted a meta-analysis of demographic and health survey (DHS) data sets from 30 countries in SSA to determine the prevalence and factors associated with the use of antibiotics in children with non-bloody diarrhoea.

\section{METHODS}

Data source

We conducted a meta-analysis of DHS data on the treatment of non-bloody diarrhoea with antibiotics in children under the age of 5 in 30 countries in SSA. DHS are nationally representative household surveys 


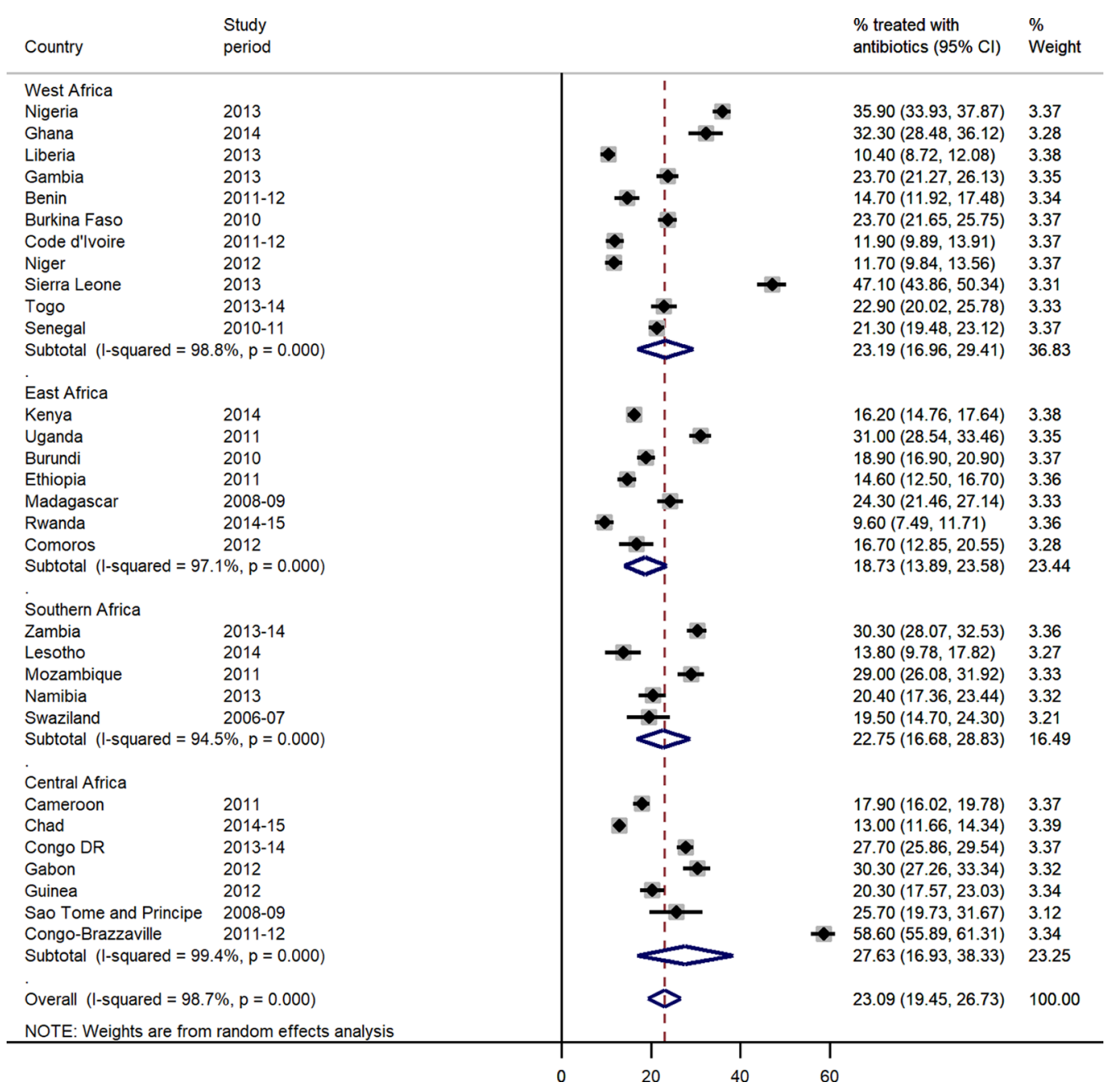

Figure 1 Meta-analysis for the prevalence of antibiotic use among cases of non-bloody diarrhoea.

conducted by ICF Macro/MEASURE DHS on behalf of national ministries of health with financial support from many international partners including the United States Agency for International Development. ${ }^{10}$ The standard DHS uses identical methodology including the probability sampling strategy and survey instrument to collect data that are comparable across countries.

Our study only included country data sets that were collected from 2000 to 2016 and contained disaggregated data on the type of diarrhoea-bloody and non-bloody diarrhoea in children under the age of 5 . The data sets of 38 countries in SSA were available from DHS programme website. Of these 38 data sets, 30 met the inclusion criteria. Details of the included countries are contained in figure 1.

\section{Data analysis}

All DHS data sets were downloaded with permission from the DHS programme website and the data were analysed using Stata V.14 and Microsoft Excel 2016.

The variables from the DHS data sets extracted and included in our analysis were prevalence of children with diarrhoea; type of diarrhoea, whether bloody or non-bloody; proportion of children treated/untreated; proportion of children who were treated for diarrhoea and type and sources of treatment. Other variables included were the sociodemographic characteristics of children and their households including age and sex of child, mother's educational level, wealth index of households, type and geographical location of child's residence.
We employed a random effects meta-analysis to calculate pooled prevalence estimates of the use of antibiotics in children with diarrhoea. A random effects meta-analysis was used because it allows for heterogeneity across studies. Despite the similarity of the DHS study design across countries, we expected heterogeneity due to differing population parameters including geographical distribution and socioeconomic conditions in different countries and regions of SSA. A test of heterogeneity of the DHS data obtained for the different countries showed a high level of inconsistency $\left(\mathrm{I}^{2}>50 \%\right)$ thereby agreeing with our decision to use the random effects model in our analysis. Furthermore, we performed sensitivity analysis by excluding from our analysis one country data at a time and the impact of excluding the data was evaluated on the summary results. This was done to examine the effect of outliers and test the robustness of our findings.

Subgroup analyses were performed to determine whether factors such as sex, age, type of residence, wealth index, education and sources of care were associated with the use of antibiotics in children under 5 years of age in SSA. The $\mathrm{X}^{2}$ tests for association or where appropriate for trend were calculated and results were considered statistically significant at $\mathrm{p}<0.05$.

\section{RESULTS}

The data sets from the 30 countries covered 287624 children under 5 years of age. Overall, the pooled prevalence of all types of diarrhoea was $15.7 \%$ (95\% CI $14.0 \%$ to $17.4 \%$ ), 
while the prevalence estimate for non-bloody diarrhoea was $12.8 \%$ (95\% CI $11.4 \%$ to $14.2 \%$ ). The majority of the cases of non-bloody diarrhoea were attended to in government health centres $(17.6 \%)$, government hospitals $(8.9 \%)$, government health posts or dispensaries (7.4\%), shops (6.6\%), community pharmacies $(4.0 \%)$ and private hospitals/clinics $(3.8 \%)$.

The pooled prevalence of antibiotic use among cases of non-bloody diarrhoea in children under 5 years of age was 23.1\% (95\% CI 19.5 to 26.7). Antibiotics were commonly used among cases of non-bloody diarrhoea in Congo-Brazzaville $58.6 \%$ (95\% CI 55.9\% to $61.3 \%$ ) and Sierra Leone $47.1 \%$ (95\% CI $43.9 \%$ to $50.3 \%$ ) (figure 1 ). The regional estimate was lowest in east Africa, 18.7\% (95\% CI 13.9\% to $23.6 \%)$ and highest in central Africa, 27.6\% (95\% CI $16.9 \%$ to $38.3 \%$ ). The higher estimate in central Africa was due to the contribution of Congo-Brazzaville. The sensitivity analysis conducted by excluding the Congo-Brazzaville data yielded a pooled estimate of $21.8 \%$ in the central region, which is comparable to southern African region. The SSA pooled estimate obtained following the sensitivity analysis $(21.9 \%$; $95 \%$ CI $18.8 \%$ to $24.9 \%)$ was comparable to our previous estimate.

Table 1 summarises the data based on the subgroup analyses performed. The subgroup analyses suggested that the use of antibiotics in children with non-bloody diarrhoea in SSA was significantly associated with $(p<0.05)$ the source of care, type of residence, wealth index, maternal education and breastfeeding status. The results revealed that antibiotics were commonly used in children who sought advice or treatment from private hospitals/clinic and community pharmacies with pooled estimates of $41.1 \%$ (95\% CI $34.1 \%$ to $47.4 \%$ ) and $41.8 \%$ (95\% CI $34.8 \%$ to $48.9 \%$ ), respectively.

\section{DISCUSSION}

The main contributions of our study lie in the use of nationally representative data, the comprehensiveness of the factors explored and the application of meta-analysis to provide pooled estimates on the prevalence of antibiotic use in episodes of non-bloody diarrhoea in children under the age of 5 in SSA. We found a high use of antibiotics to treat episodes of non-bloody diarrhoea in children under the age of 5 in SSA: over one in five cases of non-bloody diarrhoea were treated with antibiotics. Most cases of non-bloody diarrhoea in children are self-limiting and caused by microorganisms which are not susceptible to antibiotic therapy such as rotavirus or for which the efficacy of antibiotic therapy is somewhat uncertain such as in campylobacter infections. ${ }^{911} \mathrm{Up}$ to $13 \%$ of cases of non-bloody diarrhoea are due to Shigella spp or enteroinvasive Escherichia coli, ${ }^{12}$ which may justify antibiotics in children with severe toxicity or systemic symptoms of sepsis. However, the high rates of antibiotic prescribing seen in many SSA countries cannot be justified by the data on the aetiology of non-bloody diarrhoea and will only lead to antibiotic resistance and antibiotic-associated diarrhoea. Therefore, our findings underscore the need to educate both prescribers and parents in SSA on appropriate management of diarrhoea and the consequences of inappropriate use of antibiotics in children.

This study, however, is not without limitations. Some countries in SSA were not included due to non-availability of DHS data for the study period considered. Also, the data used in this study was based on self-reported data and so liable to recall and social desirability biases which may result
Table 1 Prevalence of antibiotic use in non-bloody diarrhoea by demographic category

\begin{tabular}{|c|c|c|c|}
\hline Category & $\begin{array}{l}\text { Number of } \\
\text { children with } \\
\text { non-bloody } \\
\text { diarrhoea }\end{array}$ & $\begin{array}{l}\text { Prevalence estimate } \\
\%(95 \% \mathrm{Cl})\end{array}$ & $\begin{array}{l}\text { Test for } \\
\text { association or } \\
\text { trend }\end{array}$ \\
\hline \multicolumn{4}{|l|}{ Sex of child } \\
\hline Male & 18268 & 23.5 (19.9 to 27.1$)$ & \multirow{2}{*}{$\begin{array}{l}X^{2}=1.778 \\
p=0.182\end{array}$} \\
\hline Female & 16809 & 22.9 (16.2 to 39.8$)$ & \\
\hline \multicolumn{4}{|l|}{ Age of child } \\
\hline 0 & 9307 & 21.1 (17.6 to 24.5$)$ & \multirow{5}{*}{$\begin{array}{l}X^{2}=0.018 \\
p=0.893\end{array}$} \\
\hline 1 & 11395 & $25.0(21.2$ to 28.8$)$ & \\
\hline 2 & 7040 & 22.9 (18.9 to 26.9$)$ & \\
\hline 3 & 4413 & 22.1 (18.0 to 26.2 ) & \\
\hline 4 & 2922 & 22.0 (17.8 to 26.2$)$ & \\
\hline \multicolumn{4}{|l|}{ Currently breastfeeding } \\
\hline No & 13160 & 24.1 (20.0 to 28.2$)$ & \multirow{2}{*}{$\begin{array}{l}X^{2}=13.485 \\
p<0.001\end{array}$} \\
\hline Yes & 21917 & 22.4 (18.9 to 26.0$)$ & \\
\hline \multicolumn{4}{|l|}{ Type of residence } \\
\hline Urban & 10771 & $26.7(22.5$ to 31.0$)$ & \multirow{2}{*}{$\begin{array}{l}X^{2}=109.137 \\
p<0.001\end{array}$} \\
\hline Rural & 24306 & $21.6(18.2$ to 25.1$)$ & \\
\hline \multicolumn{4}{|l|}{ Wealth index* } \\
\hline Poor & 16596 & 20.7 (16.9 to 24.5$)$ & \multirow{3}{*}{$\begin{array}{l}X^{2}=176.047 \\
p<0.001\end{array}$} \\
\hline Middle & 6789 & $22.0(18.6$ to 25.5$)$ & \\
\hline Rich & 11668 & 27.6 (23.6 to 31.6$)$ & \\
\hline \multicolumn{4}{|c|}{ Mother's highest level of education* } \\
\hline No education & 14740 & 20.5 (17.2 to 23.8$)$ & \multirow{4}{*}{$\begin{array}{l}X^{2}=184.584 \\
p<0.001\end{array}$} \\
\hline Primary & 12360 & $24.0(20.4$ to 27.7$)$ & \\
\hline Secondary & 7352 & 27.9 (23.3 to 32.4$)$ & \\
\hline Higher & 611 & 33.0 (26.1 to 39.8$)$ & \\
\hline \multicolumn{4}{|l|}{ Sources of care* } \\
\hline Government hospitals & 3131 & 38.5 (32.3 to 44.8$)$ & \multirow{10}{*}{$\begin{array}{l}X^{2}=3447.205 \\
p<0.001\end{array}$} \\
\hline $\begin{array}{l}\text { Government health } \\
\text { centres }\end{array}$ & 6184 & $35.2(29.9$ to 40.4$)$ & \\
\hline $\begin{array}{l}\text { Government health } \\
\text { posts/dispensaries }\end{array}$ & 2603 & 30.9 (24.4 to 37.5$)$ & \\
\hline $\begin{array}{l}\text { Private hospitals/ } \\
\text { clinics }\end{array}$ & 1347 & 41.1 (34.1 to 47.4$)$ & \\
\hline $\begin{array}{l}\text { Community } \\
\text { pharmacies }\end{array}$ & 1391 & 41.8 (34.8 to 48.9$)$ & \\
\hline Shops & 2321 & 33.6 (25.5 to 41.7$)$ & \\
\hline Markets & 1236 & 21.6 (6.9 to 36.3$)$ & \\
\hline $\begin{array}{l}\text { Traditional } \\
\text { practitioners }\end{array}$ & 1011 & 5.0 (3.6 to 6.5$)$ & \\
\hline Others & 1626 & 16.8 (11.8 to 21.9$)$ & \\
\hline $\begin{array}{l}\text { Did not seek treatment } \\
\text { from any provider }\end{array}$ & 14189 & 9.3 (7.3 to 11.2$)$ & \\
\hline
\end{tabular}

in underestimation of the prevalence of antibiotics used in non-bloody diarrhoea. Despite these limitations, this study provides additional insight into the management of diarrhoea in SSA and could prompt appropriate health system response.

Acknowledgements The authors gratefully appreciate ICF International, USA, for providing the NDHS data sets for this study.

Contributors AA conceived and designed the study. All authors oversaw its implementation. AA and DA planned and carried out the analyses. AA, BO and EO wrote the initial draft and all authors contributed writing to subsequent versions of the manuscript. All authors reviewed the study findings, read and approved the final version of the manuscript before submission. 
Funding The authors have not declared a specific grant for this research from any funding agency in the public, commercial or not-for-profit sectors.

\section{Competing interests None declared.}

Provenance and peer review Not commissioned; internally peer reviewed.

(c) Article author(s) (or their employer(s) unless otherwise stated in the text of the article) 2019. All rights reserved. No commercial use is permitted unless otherwise expressly granted.

\section{REFERENCES}

1 Liu L, Oza S, Hogan D, et al. Global, regional, and national causes of child mortality in 2000-13, with projections to inform post-2015 priorities: an updated systematic analysis. Lancet 2015:385:430-40.

2 Walker CL, Rudan I, Liu L, et al. Global burden of childhood pneumonia and diarrhoea. Lancet 2013:381:1405-16.

3 Carvajal-Vélez L, Amouzou A, Perin J, et al. Diarrhea management in children under five in sub-Saharan Africa: does the source of care matter? A countdown analysis. BMC Public Health 2016;16:830

4 Perin J, Carvajal-Velez L, Carter E, et al. Fluid curtailment during childhood diarrhea: a countdown analysis. BMC Public Health 2015;15:588.
5 Diallo AF, Cong X, Henderson WA, et al. Management of childhood diarrhea by healthcare professionals in low income countries: an integrative review. Int J Nurs Stud 2017;66:82-92.

6 World Health Organization. The treatment of diarrhoea: a manual for physicians and other senior health workers. 2005 http://apps.who.int/iris/bitstream/10665/43209/1/ 9241593180.pdf (accessed 02 Oct 2017).

7 Diniz-Santos DR, Silva LR, Silva N. Antibiotics for the empirical treatment of acute infectious diarrhea in children. Braz J Infect Dis 2006;10:217-27.

8 Rogawski ET, Platts-Mills JA, Seidman JC, et al. Use of antibiotics in children younger than two years in eight countries: a prospective cohort study. Bull World Health Organ 2017:95:49-61.

9 Opondo C, Ayieko P, Ntoburi S, et al. Effect of a multi-faceted quality improvement intervention on inappropriate antibiotic use in children with non-bloody diarrhoea admitted to district hospitals in Kenya. BMC Pediatr 2011;11:109.

10 Measure DHS. Methodology: survey process. http://dhsprogram.com/What-We-Do/ Survey-Process.cfm (accessed 16 May 2017).

11 O'Ryan G M, Ashkenazi-Hoffnung L, O'Ryan-Soriano MA, et al. Management of acute infectious diarrhea for children living in resource-limited settings. Expert Rev Anti Infect Ther 2014:12:621-32.

12 Liu J, Platts-Mills JA, Juma J, et al. Use of quantitative molecular diagnostic methods to identify causes of diarrhoea in children: a reanalysis of the GEMS case-control study. Lancet 2016;388:1291-301. 